\title{
Principles for Deep Knowledge and its Relationships with Integrative Orientation, Motivational Intensity and English Learning Achievement
}

\author{
I-Chin Nonie Chiang \\ Foreign Language Center, National Chengchi University, Taiwan, China
}

Copyright $\bigcirc 2018$ by authors, all rights reserved. Authors agree that this article remains permanently open access under the terms of the Creative Commons Attribution License 4.0 International License

\begin{abstract}
Nine Principles for Deep Knowledge (PDKs) have been identified as an effective method to expand an individual's Habitual Domains (HDs), which in a broader sense improves learning. This study examines the relationship between Principles of Deep Knowledge and two classical variables, i.e. Integrative Orientation and Motivational Intensity (a.k.a. effort), as well as investigates the relationships among these three constructs and English learning achievement. A total of 194 tertiary education students participated. Overall, the results suggested that the three tested variables correlated and can predict achievement, with more than half of the subscales of Principles for Deep Knowledge. Further analysis showed that Integrative Motivation and Motivational Intensity can predict learning achievement whereas Deep and Down, Alternating and Changing, and Transforming principles can predict Integrative Orientation. Deep and Down and Contradiction can predict Motivation Intensity. The findings show the potential status of PDK as a new alternative measure and predictor, closely relating with the other two constructs. Limitations, pedagogical suggestions, and future study areas are given at the end of this study.
\end{abstract}

Keywords Integrative Orientation, Motivational Intensity, Habitual Domain, Principles for Deep Knowledge, Language Learning Achievement

\section{Introduction}

Imitating successful experiences is an effective and efficient way of learning. Finding features of successful experiences can avoid unnecessary errors and be less time-consuming. This is also true in language learning research. We learn about the importance of motivation and the features of success from past research. The current study explores a relatively new feature concept for successful learning, i.e. the Principles for Deep
Knowledge in habitual domains and its relationships with motivational constructs and learning achievement through quantitative analysis. The value of this research lies in providing an original and pioneering perspective in interdisciplinary research and also supporting the theory of habitual domains and Principles for Deep Knowledge with quantitative evidence, such as questionnaire data, the literature has lacked so far [1].

\section{Literature Review}

People approach pleasure and avoid pain, and this is certainly true in the case of learning. How to initiate autonomous learning has been under research for decades along with self-motivational strategies [2]. Nevertheless, self-motivated learning does not always happen automatically; thus, researchers in different fields have been investigating variables regarding motivation and yielding a wide range of results. Among the variables, this paper starts with three core elements of motivation, i.e. what makes a person make certain choices, wants to engage in actions, and put in efforts to maintain the action $[2$, p. 3], and how they are related to learning achievement.

\subsection{Integrative Orientation}

Motivational studies concern three elements: (1) the choice of a particular action, (2) the persistence with it, and (3) the effort expended on it [2-3]. That is, researchers try to find out what initiates and maintains an action and how much time and energy a person is willing to spend on it. Therefore, the following section begins with a review of Integrative Orientation, which highly relates to one's choice of an action, followed by the Motivational Intensity, i.e. the effort one's willing to put in, and ends with the introduction of Principles for Deep Knowledge, which concerns how people make decisions and maintain 
the action until it becomes a habit.

Research on motivation has experienced shifts of research focus since the early pioneering work of Gardner and Lambert, e.g. the social psychological period (19591990), the cognitive-situated period (late 1980s-1990s), and the process-oriented period (2000s-) to the recent socio-dynamic period [4]. Regardless of the periods, the classic model of Gardner and Lambert's Integrative and Instrumental Orientations [5] has received the most empirical attention and still stands as the most well-known concept in motivational research. Integrative Orientation refers to "the desire to interact with and even become similar to valued member of that community" [5, p. 271], while the Instrumental Orientation refers to reasons that reflect practical purposes in learning a second language (L2), e.g. passing an exam. Gardner and Lambert [6] suggested that Integrative Orientation was a better predictor or the ultimate achievement than the Instrumental Orientation for it as the positive attitudes from within the learners and is more likely to create a positive cycle in learning. For years, the notion of Integrative Orientation has generated criticisms due to the over-simplified explanation for such a complex concept. For instance, many other orientations exist (e.g. Clément and Kruidenier [7]), while intrinsic motivation factors such as enjoyment and interest alone might not be strong enough to sustain learning [8]. Nonetheless, Dörnyei and Clément [9] still found integrativeness to be the most powerful component of participants' language disposition, language choice, and the effort expended, i.e. the 'Motivational Intensity' [10] in section 2.2. After his large-scale motivation survey targeting over 13,000 Hungarian learners [11], Dörnyei [12] proposed the L2 Motivational Self- System, consisting of the Ideal L2 Self, the Ought-to L2 Self, and the L2 Learning Experience. The Ideal L2 Self refers to one's level of desire to decrease the discrepancy between one's actual self and one's native-like self, which is in the same vein of Integrative Orientation, whereas the ought-to L2 self and the L2 Learning Experience refer to the social pressure to meet expectations and potential influence of the environment, respectively.

\subsection{Motivational Intensity}

Learners must invest time and energy to realize the Ideal L2 Self mentioned above, because arousing and possessing interest does not guarantee success [13, p. 121]. Past research has identified ability and effort (termed as 'Motivational Intensity' in Attitude/Motivation Test Battery, [10]) as the most dominant perceived causal attributions in academic settings [14-15]. People who have strong desire to become native-like are more willing to put in an effort in learning, which seems to likely lead to better achievement. Effort becomes extremely important especially when the target of interest is a sustained learning process, such as the mastery of a second language, which may take several years to accomplish. Since our behavior is the representation of our mind, once a person stops making an effort, one's proficiency stops improving, or even backslides. Language acquisition needs target language exposure and it is difficult to maintain exposure in an EFL context such in Taiwan; it takes effort to keep contact with language input.

\subsection{Principle for Deep Knowledge (PDK) and Language Learning}

After understanding the importance of motivation orientation and effort, the next question to ponder is how to change the hard effort of language learning into a pleasant life-long habit. This involves changing one's mindset. A learning theory that can enhance the motivation to pursue a certain goal is needed because motivation triggers behavior and the theory of habitual domain may be a good example.

In theory, human brain bestows unlimited potentials of thoughts and behavior upon human. Unfortunately, we are often prone to and stuck with fixed thoughts and routine behavior, losing adaptability, rigidly adhering to certain thinking logic, which gradually reducing our potentials [16]. $\mathrm{Yu}$, from the findings in a variety of scientific disciplines, including neuroscience, psychology, system science, management and administration science, developed the theory of Habitual Domains (HD) based on statistical evidence [16].

The basic concept of HD is that memories, concepts, behaviors and reactions gradually become stable over time and stay in a fixed range [16]. These thoughts and behaviors, which dictate our behavior, is our habitual domain $[16$, p. 2]. Unless something extraordinary happens, our HD is unlikely to change or expand and this makes us predictable and sterile [16, p. 3]. According to the HD theory, there are four essential components: the potential domain (PD), the actual domain (AD), the activation probability (AP), and the reachable domain (RD). To help understand the concept, let me take language learning as an example to explain it clearer. Potential domain (PD), which is the aggregation of all the power grids, i.e. the thoughts and ideas potentially available, in our mind, refers to all the linguistic competence we possess. Actual domain (AD) is the current level of proficiency or linguistic performance. In addition, the $\mathrm{AD}$ includes a part that underlines our behavior, the Observable Domain (OD), which is like the observable performance in a given context. Activation probability (AP) refers to the probability of all thoughts, concepts, and actions in a potential domain will actually be used, e.g. giving a certain response to a question in class. Finally, a reachable domain (RD) is the extension of ideas and thoughts triggered by the actual operations of these ideas and thoughts, which may refer to the reorganization of mental grammar and hypothesis testing in the next usage. In short, our HD includes an enormous 
yet expanding $\mathrm{PD}$, which consists of $\mathrm{RD}$ and $\mathrm{AD}$, which contains a smaller OD. Interestingly, this hierarchy coincides with the well-known 'comprehensible input' hypothesis [17-18]. In language acquisition, when a learner's current level is ' $i$ ', we should provide input at ' $i+1$ ' level (one level beyond) for language acquisition to take place. This ' $i+1$ ' input catches learners' attention on the new forms, which triggers a chain action of comparing and contrasting the old and new knowledge, analyzing the reasons why they are different, and testing the new hypothesis in the next usage. When the new hypothesis is tested out and after a few practices, the information will be internalized, upgrading from $\mathrm{AD}$ to $\mathrm{RD}$ or PD. Figure 1 illustrates the hierarchy of HD elements in relation to Krashen's comprehensible input hypothesis [19].

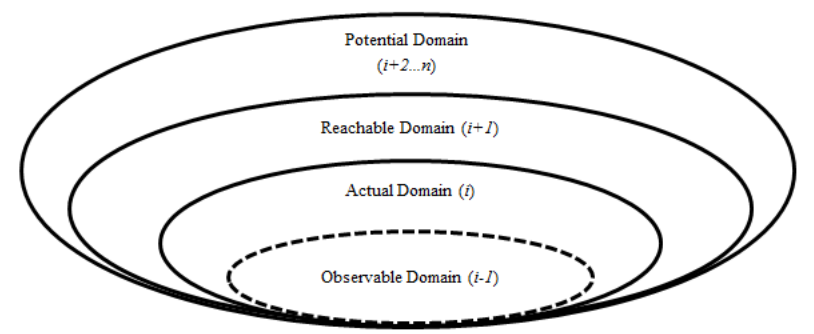

Figure. 1. HD elements in relation to comprehensible input hypothesis [19-20]

HD theory considers "circuit patterns" as the key to HD expansion. Similar to the brain cells, the circuit patterns have the "use it or lose it" feature. If the circuit patterns are strengthened through regular access and exercise, they will assist in giving appropriate and correct 'intuitive' decision when the time comes [16].

In short, what we call 'learning' is the result of repeated expansion of actual domain, reachable domain, and potential domain. $\mathrm{Yu}$ [21] coined the term 'working knowledge mining' because "the process of obtaining or creating good ideas for solving the challenging decision problems is like mining diamond or gold in the relevant fields" [21, p. 731]. Furthermore, Yu [22] pointed out the three stages in the learning process: implanting, nurturing, and habituating, which refer to knowledge construction, internalization the knowledge through memorizing and reproducing, and application of the acquired knowledge. This coincides with the logic of the current research in that we first learn why we choose to do something, and then we internalize the concept and make an effort to maintain the action. Finally, we want to develop a habit based on the action.

In the literature of $\mathrm{HD}$, the 'Principles for Deep Knowledge (PDK)' have been identified as an effective way to expand an individual's HD, which means to change or foster one's habit [16]. The nine Principles for Deep Knowledge are defined [16, 21-23] and elaborated in relation to language learning as follows [20, 24]. Chiang [19-20, 24] has further discussions on the relationship between the Principles for Deep Knowledge and language learning.

Deep and Down Principle. Two layers of meanings are embedded with this principle. Firstly, to liberate desires and reduce stress levels so that the weaker power grids may attract our attention. Secondly, keep a humble attitude for more and better ideas to expand the habitual domain. Interactive classroom learning is common since the popularity of communicative language teaching approach. Student tasks are often to solve a problem, share experiences, ask for advice, etc. When they ask for advice from peers or the teacher, they are reaching out with an inferior attitude and releasing stress to struggle alone, which could lead to giving up in some cases.

Alternating Principle. Setting aside presumptions, hypotheses, or prejudices could help us come up with new and inspiring ideas. Language learners seldom only repeat limited existing sentences and spend lots of time constructing and producing novel sentences while testing linguistic knowledge, i.e. the syntax, they have, which is similar to first language acquisition, especially in a language classroom. For instance, different prepositional phrases (with the structure of a preposition before a noun phrase) produce various meanings when the preposition changes.

Contrasting and Complementing Principle. Contrasting ideas may also be complementary and we should think beyond the surface or literal meaning. Differentiating between tenses in English and learning synonyms and antonyms are good examples of deep thinking.

Revolving and Cycling Principle. The universe revolves in cycles constantly. So does the process of expansion for habitual domains and learning as mentioned earlier. Vocabulary buildup requires distributed and incremental contacts with the target language [25]. Leaning a word requires several contacts with the word; and for each contact, we learn a certain aspect of the word. Gradually, we accumulate the knowledge and know the word. Unfortunately, if we leave the word intact without access for a certain period of time, there is a high risk that the word would withdraw from our memory and become unfamiliar or unavailable. Then, another cycle of vocabulary buildup will have to take place. When a learner has to repeatedly learn a word, the emotional ups and downs cannot be avoided and are likely to influence the motivation in learning.

Inner Connection Principle. It is necessary to enhance powerful connectivity in learning and the more, the merrier. This allows more quick and effective access of our habitual domains and shortens the time needed to find effective resolutions to problems. Connecting and associating old and new knowledge is the most effective learning method; for example, learning vocabulary using the method of word root and prefixes or suffixes.

Changing and Transforming Principle. People change when they need to adapt to a new situation or environment. Each change is a challenge and proof of the activation and expansion of our habitual domain. Our ability to change 
and adapt evolves at the exponential rate because of the advancement of technology. Our HDs expand even faster after the multimedia instruction has become an inevitable trend in academia. For instance, computer-assisted language teaching (CALL), MOOCS, or SPOCS are incorporated into academic curriculum in the higher education nowadays to initiate and increase the opportunities for autonomous extracurricular learning. Nonetheless, in addition to the ability to change and transform, it should be noted that the ability to change at ease and under control is equally crucial in learning to avoid side effects such as information overloading and information anxiety syndrome.

Contradiction Principle. Looking at things from various viewpoints can help learners think in various dimensions. When a learner finds a counterexample, s/he must re-evaluate and modify the conclusion to ensure the robustness of the judgment. This is training for analytical and critical thinking skills. This principle enables learners to realize that positive attitude and effort do not necessarily guarantee high final grades [1]. Additionally, wanting to do something is different from doing it. Learners often have high motivation in learning but spend fewer hours learning is another example of this principle $[19,24]$.

Cracking and Ripple Principle. Habitual domains consist of a large number of microsystems, and occasionally they may conflict with each other and cause cracks, i.e. the sources of problems. When inconsistencies between subsystems happen, we should look for change for solutions and improvements. This triggers changes in and expands habitual domains. "A common strategy to improve learning is focusing on an unfamiliar area or an area with lower scores to improve our knowledge weakness" [1, p. 2]. For instance, English idioms are a string of fixed words that contain non-literal but idiomatic meanings. These idiomatic meanings are often distant from the original meaning of the words and baffle students. Memorizing idioms is an action to expand HD and putting idioms into use habituates the knowledge in the mindset.

Void Principle. It is important to let go some of the constraints of existing thought so new knowledge can enter our habitual domains, whether it is an individual's own new thoughts or those from others. While facing a challenge, one cannot provide with the most effective and appropriate response because this is something outside one's habitual domain. Void principle stresses on the impact of another's habitual domain in our habitual domain expansion process. For instance, asking the advice from a professional proofreader is an effective action.

In the process of investigating why some learners outperform others, all things being equal, Chiang [24, 26] indicated that students with strong learning outcomes exhibit these nine deep knowledge principles, evidencing a close relationship between learning achievement and the Principles for Deep Knowledge through questionnaire survey. In theory, the expansion of habitual domains helps us to change our choices. Practice through Principles for Deep Knowledge can reinforce behavior into habits. Lin, Huang and Hsiung [1] claim that deep knowledge principles can be used as psychometric scales to measure individual learning features during the learning process through quantitative analysis of 785 high school students in Taiwan. These principles should be considered learning features to develop one's own awareness of one's own weaknesses and strength to improve learning effectiveness. Chiang [24], while investigating the possible influence of deep knowledge between the reading habit and learning achievements, has not shown a direct significant mediating effect of the Principles for Deep Knowledge on reading habit, which is possibly due to a small sample size (32 randomly selected participants). However, the result of stepwise multiple regression analysis shows that at least one principle, the inner-connection, principle has significant predictive power over learning achievements $\left(\mathrm{R}^{2}=.23, \beta=-.51, p<.05\right)$. This sheds light on the possible indirect influence of PDK on language learning. Thus, implanting the knowledge of Principles for Deep Knowledge in learners is still of paramount importance because they need to possess certain learning features (e.g. Principles for Deep Knowledge) to enhance motivation and regulate behavior. Teachers' responsibility is to provide this knowledge to learners beforehand, so it is available when the learners' initial motivation starts to disappear. Research on interventions using Principles for Deep Knowledge during the learning process and to what extent this will influence learning is worth deeper investigation.

\section{The Current Study}

The above studies $[1,24,26]$ suggested the importance of exploring to what extent PDK as learning features can influence whether directly or indirectly a criterion variable, in this case language learning, while in Lin, Huang and Hsiung's [1] is learning effectiveness. After all, PDK is a comparatively newly but well developed theory. It has been applied in many business and management courses to encourage positive thinking and rid bad habits. Therefore, the author sees the value in it to encourage learner motivation and change learner habits of Taiwanese tertiary students. The current study examines the links for the three variables (Integrative Orientation, Motivation Intensity, and Principles for Deep Knowledge) within themselves and with English learning achievement. Most important of all, the author wants to investigate if PDK is an effective predictor of learning achievement. Only a handful of research studies have explored the connection between English learning and the principles of deep knowledge in habitual domains, among which potential theoretical connections are discussed. Unlike these other studies, the current study aims to justify these connections with quantitative analysis results step-by-step. First, the 
author proposes that Integrative Orientation, Motivational Intensity, and the Principles for Deep Knowledge would positively correlate to each other to show they are constructs with tight connections. Secondly, if the correlation is confirmed, the author proposes that these three constructs would correlate to English learning achievement. The previous literature suggested that the higher these constructs score, the better achievement learners should possess. Next, the author expects that Integrative Orientation and Motivational Intensity would be significant predictors of English learning achievement based on the past literature. Finally, whether the nine principles of deep knowledge would be significant predictors of Integrative Orientation and Motivational Intensity is put under statistical examination.

\section{Method}

\subsection{Participants and Procedure}

The participants were 194 Taiwanese university students and consisted of 114 males and 80 females. Participants were recruited through English classes. During one academic semester, participants completed the questionnaire in the classrooms. Participants were given an introduction by the author and gave their informed consent to complete the questionnaire without reimbursement. It took about 30 minutes to fill in the questionnaire. All participants were treated in accordance with APA ethical standards.

\subsection{Materials}

\subsubsection{Integrative Orientation}

The Attitude/Motivation Test Battery (AMTB) is a research instrument developed to measure the affective components specifically in second language learning. It has different subscales, but only two specific concepts are included in the current study: the Integrative Orientation and the Motivational Intensity. All items are translated and into Chinese, the participants' mother tongue, to facilitate comprehension. The four items in the Integrative Orientation scale emphasize the importance of learning French in order to permit social interaction with French Canadians or others who speak French in Gardner [10]. In the current case, the target language is English instead. The measurement used a five-point scale ranging from 1 (strongly disagree) to 5 (strongly agree). A high score on this scale indicates that a student possesses more intrinsic reasons for studying the language. An example item is: "Studying English can be important for me because it will enable me to better understand and appreciate English art and literature".

\subsubsection{Motivational Intensity}

This measure consists of 10 multiple-choice items that are designed to measure the effort a student puts into learning the language. The items are scored following the scoring key provided between 1 and 3 points. A high score means a student's high degree of effort devoted to acquiring the language. An example item is "Considering how I study English, I can honestly say that I: a) do just enough work to get along (2 points); b) will pass on the basis of sheer luck or intelligence because I do very little work (1 point); c) really try to learn English (3 points)".

\subsubsection{Principles for Deep Knowledge Scale}

This was measured with a 30 -item measurement, which used a five-point scale ranging from 1 (strongly disagree) to 1 (strongly agree). The Principles for Deep Knowledge are considered positive features for more successful learning. Thus, a high score that represents stronger and more strengthened deep knowledge usage is more likely to result in higher learning achievement. The scale was initially comprised of 32 items, but was later rephrased into 30 for better face validity, content validity, concurrent validity, and internal consistency $(\alpha=.86$; [26]). In the current study, an item analysis was conducted to test the effectiveness of the items before the validity test.

\subsubsection{English Learning Achievement}

With participant consent, the current research refers to the participant's end-of-semester academic scores as learning achievements. Overall learning achievement was indicated by five points of students' grade point average, 5 for a score of 90 and above, 4 for a score between 80 and 89,3 for a score between 70 and 79,2 for a score between 60 and 69 , and 1 for a score below 60 .

\subsubsection{Statistical Analysis}

The statistical analyses were performed with SPSS 20.0. Descriptive statistics (means, standard deviations) for all measures were calculated. Pearson Product Moment Correlations were computed among the Integrative Orientation, Motivational Intensity, and the factors of the Principles for Deep Knowledge. Linear regression analysis was used to determine the relationships between learning achievement and both Integrative Orientation and Motivational Intensity, and between the subscales of the Principles for Deep Knowledge and both Integrative Orientation and Motivational Intensity.

\section{Results}

Table 1 presents the means, standard deviations, reliabilities, validities, and inter-correlations. English learning achievement had an average score of 83.15 (s.d. 9.004). The mean values of Integrative Orientation, Motivational Intensity, and the factors of the Principles for Deep Knowledge indicated high mean values (above the midpoint). 
Table 1. Mean, SD, Cronbach's $\alpha$ and Correlations between Variables

\begin{tabular}{|c|c|c|c|c|c|c|c|c|c|c|c|c|c|c|}
\hline & mean & SD & $\alpha$ & 1 & 2 & 3 & 4 & 5 & 6 & 7 & 8 & 9 & 10 & 11 \\
\hline 1.achievement & 83.15 & 9.00 & & & & & & & & & & & & \\
\hline 2.Integrative Orientation & 4.30 & 0.57 & 0.77 & $.271^{* *}$ & & & & & & & & & & \\
\hline 3.Motivation intensity & 2.25 & 0.25 & 0.59 & $.484^{* *}$ & $.304^{* *}$ & & & & & & & & & \\
\hline 4.Deep and Down & 4.04 & 0.49 & 0.52 & -.027 & $.407^{* *}$ & $.287^{* *}$ & & & & & & & & \\
\hline 5.Alternating & 4.13 & 0.54 & 0.64 & $.185^{*}$ & $.486^{* *}$ & $.270^{* *}$ & $.545^{* *}$ & & & & & & & \\
\hline 6.Contrasting and Complementing & 3.90 & 0.54 & 0.40 & $.153^{*}$ & $.205^{* *}$ & $.291^{* *}$ & $.286^{* *}$ & $.224^{* *}$ & & & & & & \\
\hline 7.Revolving and Cycling & 3.92 & 0.54 & 0.38 & .075 & $.248^{* *}$ & $.254^{* *}$ & $.343^{* *}$ & $.283^{* *}$ & $.380^{* *}$ & & & & & \\
\hline 8.Inner Connection & 4.03 & 0.47 & 0.57 & $.214^{* *}$ & $.290^{* *}$ & $.257^{* *}$ & $.403^{* *}$ & $.383^{* *}$ & $.591^{* *}$ & $.411^{* *}$ & & & & \\
\hline 9.Changing and Transforming & 4.09 & 0.57 & 0.68 & .062 & $.410^{* *}$ & $.264^{* *}$ & $.444^{* *}$ & $.547^{* *}$ & $.313^{* *}$ & $.405^{* *}$ & $.469^{* *}$ & & & \\
\hline 10.Contradiction & 3.96 & 0.69 & 0.84 & $.194^{* *}$ & $.276^{* *}$ & $.297^{* *}$ & $.285^{* *}$ & $.273^{* *}$ & $.674^{* *}$ & $.378^{* *}$ & $.592^{* *}$ & $.369^{* *}$ & & \\
\hline 11.Cracking and Ripping & 4.02 & 0.55 & 0.61 & .022 & $.290^{* *}$ & $.143^{*}$ & $.443^{* *}$ & $.384^{* *}$ & $.462^{* *}$ & $.390^{* *}$ & $.418^{* *}$ & $.390^{* *}$ & $.529^{* *}$ & \\
\hline 12.Void & 3.91 & 0.53 & 0.52 & $.144^{*}$ & $.298^{* *}$ & $.258^{* *}$ & $.448^{* *}$ & $.356^{* *}$ & $.369^{* *}$ & $.456^{* *}$ & $.463^{* *}$ & $.478^{* *}$ & $.470^{* *}$ & $.384^{* *}$ \\
\hline
\end{tabular}

Note. ${ }^{*} p<.05 ; * *<.01$.

Table 1 presents the results of the correlation analyses. The Integrative Orientation significantly correlated with Motivational Intensity $(r=0.30, p<0.01)$. The Integrative Orientation positively correlated with all nine scales of PDK, including Deep and Down $(r=0.41, p<$ $0.01)$, Alternating $(r=0.49, p<0.01)$, Contrasting and Complementing $(r=0.21, p<0.01)$, Revolving and Cycling $(r=0.25, p<0.01)$, Inner Connection $(r=0.29$, $p<0.01)$, Changing and Transforming $(r=0.41, p<$ $0.01)$, Contradiction $(r=0.28, p<0.01)$, Cracking and Ripping $(r=0.29, p<0.01)$, and Void $(r=0.30, p<$ $0.01)$. The Motivational Intensity were found to positively correlate with Deep and Down $(r=0.29, p<0.01)$, Alternating $(r=0.27, p<0.01)$, Contrasting and Complementing $(r=0.29, p<0.01)$, Revolving and Cycling $(r=0.25, p<0.01)$, Inner Connection $(r=0.26$, $p<0.01)$, Changing and Transforming $(r=0.26, p<$ $0.01)$, Contradiction $(r=0.30, p<0.01)$, Cracking and Ripping $(r=0.14, p<0.05)$, and Void $(r=0.30, p<$ $0.01)$. Thus, the results of this study confirmed that Integrative Orientation, Motivational Intensity, and Principles for Deep Knowledge positively correlate to each other.

Additionally, English learning achievement significantly and positively correlated with both Integrative Orientation $(r=0.27, p<0.01)$ and Motivational Intensity $(r=0.48$, $p<0.01)$. Regarding the PDK scale, five of the nine principles exhibited positive association with English learning achievement, including Alternating $(r=0.19, p$ $<0.01)$, Contrasting and Complementing $(r=0.15, p<$ 0.01), Inner Connection $(r=0.21, p<0.01)$, Contradiction $(r=0.19, p<0.01)$ and Void $(r=0.14, p$ $<0.05$ ). Therefore, the results confirmed that Integrative Orientation, Motivational Intensity positively correlated with English learning achievement; whereas more than half of the PDK exhibited a positive association with English learning achievement.

Stepwise regression analysis was performed to explore the contribution of Integrative Orientation and Motivational Intensity on English learning achievement. Regression results showed that English learning achievement was significantly predicted $\left(R^{2}=0.25, F=\right.$ $4.25, p<0.05)$ by Integrative Orientation $(\beta=0.14, p<$ $0.05)$ and Motivational Intensity $(\beta=0.48, p<0.01)$. Thus, the author's proposal on Integrative Orientation and Motivational Intensity being significant predictors of English learning achievement were sustained.

The relationship between the subscales of PDK and two factors were further examined because the PDK positively correlated with Integrative Orientation and Motivational Intensity. The results of the linear regression analyses indicated that a number of the PDK subscales significantly predicted Integrative Orientation and Motivational Intensity. Integrative Orientation, as the dependent variable, was significantly predicted $\left(R^{2}=0.29, F=4.83, p<0.05\right)$ by Deep and Down $(\beta=0.17, p<0.05)$, Alternating $(\beta=$ $0.49, p<0.01)$ and Changing and Transforming $(\beta=0.21$, $p<0.01)$. The two principles of Deep and Down $(\beta=$ $0.22, p<0.01)$, and Contradiction $(\beta=0.30, p<0.01)$ were found to significantly predict Motivational Intensity $\left(R^{2}=0.13, F=9.63, p<0.01\right)$. The findings partially support that PDK could potentially function as a predictor of Integrative Orientation and Motivational Intensity.

\section{Discussion and Conclusion}

The current research has generated a number of valuable outcomes. First, the author has tested and confirmed the positive correlation among the Integrative Orientation, Motivational Intensity, and the Principles for Deep Knowledge to show that the principles of deep knowledge could be considered as important a learning feature like attitude. Habitual domains and Principles for Deep Knowledge are relatively new theories and have not been implemented in the EFL field, except Chiang [20, 24, 26]. 
This is one of the first research studies to examine the implementation of Principles for Deep Knowledge and English learning with quantitative evidence. The statistical result suggests that a construct such as Principles for Deep Knowledge could be treated as equally as the other two classical constructs for it demonstrates close and valuable relationships with them. In other words, the current research has shown that Principles for Deep Knowledge can be seen as effective learning features and instrument in the process of language learning.

The second step tested the relationship among the three variables (Integrative Orientation, Motivational Intensity, and Principles for Deep Knowledge) and the English learning achievement. Integrative Orientation and Motivational Intensity unsurprisingly were positively correlated with English achievement. Unfortunately, only five of the nine principles positively correlated with English achievement even though the mean points for the nine principles were all above the cut-off point of 3.5, which indicates that the participants all possessed deep knowledge. Chiang [20] investigated the mediating effect of deep knowledge on learning achievement and the results were inconclusive. With a larger sample in the current study, we are able to make one small step into understanding the relationship between deep knowledge and learning achievement. The correlation coefficients appeared weak but significant; this may be due to the first experimental use of the PDK questionnaire in the field of language learning. This instrument would certainly require more examinations and further modifications in the future. It is worth noticing that the Inner Connection Principle has demonstrated a strong correlation with learning achievement repeatedly $[24,26]$ and in addition to the results of the current study. "When we connect our thoughts and learning activities by associating with old and new knowledge and personal experiences, we respond faster and create deeper impressions. Those who have high learning achievements tend to be familiar with the English language or spend more hours learning and hence they are capable of making associations, an attribute called inner-connections." [20, p. 210] The four non-significant principles were Deep and Down, Revolving and Cycling, Changing and Transforming, and Cracking and Ripping. Possible explanations for the former two principles could be that Taiwanese students are used to the high pressure of the educational environment. Students would not let stress or emotions influence their learning. In addition, participants in the current study were from one of the leading universities in Taiwan. To enter the university, the learners generally had above average percentile rankings, possessed better English proficiency, or are harder-working students. This could potentially influence the analysis results. Regarding the Changing and Transforming principle, despite the university aggressively incorporating modern technology into the curriculum, it is the teachers who put in more effort in changing and following the policy. The students can still do well without changes in education reform. Finally, on Cracking and Ripping, scores and new learning do not necessarily relate unless learners spend time and effort for further understanding of knowledge after they receive a graded paper or exam.

The results confirm that Integrative Orientation and Motivational Intensity were significant predictors of English learning achievement. As a result, the author wants to further test if the principles of deep knowledge could predict the Integrative Orientation and Motivational Intensity, which were positively correlated with PDK. That means, if we can improve the features of the Principles for Deep Knowledge, then we can improve Integrative Orientation and motivation intensity as well (for it can predict them both). That being the case, we can also test whether this will further improve English learning achievement through the enforcement of Principles for Deep Knowledge in the learning process. The findings suggest that Deep and Down, Alternating, and Changing and Transforming predicted Integrative Orientation; while Deep and Down and Contradiction principles predicted Motivational Intensity. The current study removes the limitation of Lin, Huang and Hsiung's [1], by not examining the influence of Principles for Deep Knowledge on the academic performance and confirmed the powerful influence of the Principles for Deep Knowledge to improve learners' attitude to increase achievement.

Cheng and Dörnyei [27] pointed out that Taiwanese teachers place much more emphasis on recognizing students' efforts than promoting learner autonomy. Nonetheless, in addition to effort, the current research has shown the importance of other variables in learning, i.e. the Integrative Orientation and Principles for Deep Knowledge, which relate to the positive attitude and the maintenance of the attitude. To develop positive learning attitude does not mean to learn without pressure and only with pleasure. Teachers need to think in terms of creating the conditions for developing students' positive attitude and teaching them to make the right choice to maintain the engagement in learning, which consequently leads to autonomous learning. Meanwhile, teachers should also aim to become a 'good-enough motivator' [3]. This analogy was originally from Winnicott's [28] and was developed by Bettelheim [29], advocating, in order to produce a psychologically healthy child, that parents should only provide minimum level of support needed for healthy development and not be super-parents. Dörnyei argued that teachers should provide just the same minimum level of support needed for learning development and not strive unreasonably to become a super-motivator. To create a positive motivational classroom, quality teaching excels quantity teaching.

Individual differences play an important role in the three tested constructs, namely the Integrative Orientation, 
the Motivational Intensity, and the Principles for Deep Knowledge. In the context of classroom, it is difficult for a teacher to satisfy the needs of each student. As a result, teachers tend to make use of small group activities to deal with the difficulty. In many cases, a teacher would divide the group based on the level of proficiency, student interest, etc. However, the author suggests that teachers can consider dividing students according to their learning features, such as the Principles for Deep Knowledge. If learners are arranged based on PDK features, the teachers can know exactly what learning features learners need. Another possibility is to consider learners' level of Motivational Intensity. When a teacher groups students of similar levels of effort, this will decrease the number of free riders in the group. It might not become a problem for a high devotion group because they would work hard anyway; however, in the group with low dedication members, no one would be willing to do the work and they would have to learn to face the situation and work together eventually.

Future studies should also consider the gender differences for it could also influence the learners' attitude, Motivational Intensity, and Principles for Deep Knowledge features. Instinctively, females seem to enjoy learning languages more than males. Females might like to devote more time learning languages because of their positive attitude. Males and females may have possessed different stronger features on the subscales of deep knowledge principles. For instance, Lin, Huang and Hsiung [1] discovered that female students were more likely to implement the features of the Principle of Contrasting and Complementing and the Principle of Cracking and Ripping. Female are more likely to main good connections with classmates to better their learning and paid attention to the development of their attitudes regarding future careers. A lesson here for the teacher is to modify teaching regarding the gender differences, trying to maximize the strengths and minimize the weaknesses. Teachers in Taiwan should take this into serious consideration because the population structure has been changing with the unequal ratio between genders of newborn babies and the low birth rates. It is critical to think ahead about how to plan and adjust teaching accordingly in the near future.

Many variables can influence motivation and we cannot test each and every one of them in a single study. Even though reductionist models of motivation reduce the multitude of potential determinants of human behavior by identifying a relatively small number of key variables to explain a significant proportion of the variance in people's action, it still is able to achieve the precision in explaining the interrelationship of the constitutes, and the components can also be operationalized to allow for the empirical testing of the model [2, p. 8]. However, future research should consider using more sophisticated analyses to explore the causal relationship among the variables.

The current research is original and valuable because it is the only study that implements Principles for Deep Knowledge in the field of English learning with good reliability, validity, and sound quantitative evidence. With the results of this study, there is not much question about whether these constructs affect learning achievement, but much is yet to be learned about how they affect learning achievement.

\section{REFERENCES}

[1] M. H. Lin, M. Huang, W. Hsiung. The learning feature of deep knowledge and its relationship with exercise. Online available

http://sgo.sagepub.com/content/4/2/2158244014535415.ful ltext.pdf + html

[2] Z. Dörnyei, E. Ushioda. Teaching and researching motivation (2nd ed.), Longman, Harlow, 2011.

[3] Z. Dörnyei. Teaching and researching motivation, Pearson Education Limited, Essex, 2001.

[4] Z. Dörnyei. The psychological of the language learner: Individual differences in second language acquisition, Lawrence Erlbaum, Mahwah, NJ, 2005.

[5] R. Gardner, W. Lambert. Motivational variables in second language acquisition, Canadian Journal of Psychology, Vol.13, 266-272, 1959.

[6] R. Gardner, W. Lambert. Attitudes and motivation in second language learning, Newbury House, MA, 1972.

[7] R. Clément, B. Kruidenier. Orientations in second language acquisition: I. The effects of ethnicity, milieu and target language on their emergence, Language Learning, Vol.33, 273-291, 1983.

[8] K. Noels, L. Pelletier, R. Clément, R. Vallerand. Why are you learning a second language? Motivational orientations and self-determination theory, Language Learning, Vol.50, 57-85, 2000.

[9] Z. Dörnyei, R. Clément. Motivational characteristics of learning different target languages: Results of a nationwide survey, In Z. Dörnyei, R. Schmidt (Eds.), Motivation and Second Language Acquisition (pp. 399-432), University of Hawaii Press, Honolulu, 2001.

[10] R. Gardner. Social psychology and second language learning: The role of attitudes and motivation, Edward Arnold, London, 1985.

[11] Z. Dörnyei, K. Csizér, N. Németh. Motivation, language attitudes and globalization: A Hungarian perspective, Multilingual Matters, Clevedon, 2006.

[12] Z. Dörnyei. The L2 Motivational Self System, In Z. Dörnyei, E. Ushioda (Eds.), Motivation, Language Identity and the L2 Self (pp. 9-42), Multilingual Matters, Bristol, 2009.

[13] M. Williams, R. Burden. Psychology for Language 
Teachers, Cambridge University Press, Cambridge, 1997.

[14] S. Graham. Classroom motivation from an attributional perspective, In H. F. Jr. O’Neil, M. Drillings (Eds.), Motivation: Theory and Research, (pp. 31-48), Lawrence Erlbaum, Hillsdale, NJ, 1994.

[15] B. Weiner. An attributional theory of achievement motivation and emotion, Psychological Review, Vol.92, No.4, 548-573, 1985.

[16] B. Yu. Habitual domains: Freeing yourself from the limits on your life, Highwater Editions, Shawness Mission, KS, 1995.

[17] S. Krashen. Principles and practices in second language acquisition, Pergamon Press, New York, 1982.

[18] S. Krashen. The Input Hypothesis: Issues and Implications, Longman, London, 1985.

[19] I. N. Chiang. The habitual domain, brain research and language learning, Journal of Habitual Domains, Vol.4, No.1, 43-56, 2012.

[20] I. N. Chiang. A new interpretation of English reading activities: The implementation of the principles of deep knowledge, International Journal of Language and Linguistics, Vol.2, No.4, 152-161, 2015.

[21] B. Yu. Working knowledge mining by Principles for Deep Knowledge, International Journal of Information Technology \& Decision Making, Vol.5, 729-738, 2006.
[22] B. Yu. Habitual domains and forming winning strategies, National Chiao Tung University Press, Hsin-Chu, Taiwan, 2002.

[23] B. Yu. Decision making, habitual domains and information technology, International Journal of Information Technology \& Decision Making, Vol.1, No.1, 5-26, 2002.

[24] I. N. Chiang. Reading Habits, Language Learning Achievements and Principles for Deep Knowledge, Linguistics and Literature Studies, Vol.4, No.3, 203-212, 2016.

[25] R. Waring, M. Takaki. At what rate do learners learn and retain new vocabulary from reading a graded reader? Reading in a Foreign Language, Vol.15, No.2, 130-163, 2003.

[26] I. N. Chiang. Principles of deep knowledge and language learning, In The Proceedings of the $19^{\text {th }}$ Annual Conference of Habitual Domains (pp. 1-9), Habitual Domain Association, Taiwan, 2011.

[27] H. Cheng, Z. Dörnyei. The use of motivational strategies in language instruction: The case of EFL teaching in Taiwan, Innovation in Language Learning and Teaching, Vol.1, 153-174, 2007.

[28] D. Winnicott. The Motivational Process and the Facilitating Environment. Hogarth Press, London, 1965.

[29] B. Bettelheim. A good enough parent, Thames and Hudson, London, 1987. 